\title{
Application of load-adapted hybrid textiles for a thermoplastic seat pass-through
}

\author{
Daniel Nebel ${ }^{1)}$, Michael Schreiter'), Enrico Körner ${ }^{3)}$, Arham Saleem²), Manuel Schlegel ${ }^{4)}$
}

1) Systems and Technologies for Textile Structures STEX, daniel.nebel@iwu.fraunhofer.de, Fraunhofer Institute for Machine Tools and Forming Technology IWU, Hermann-Münch-Straße 2, 38440 Wolfsburg, Germany

2) Systems and Technologies for Textile Structures STEX, michael.schreiter@iwu.fraunhofer.de, arham.saleem@iwu.fraunhofer.de, Fraunhofer Institute for Machine Tools and Forming Technology IWU, Reichenhainer Straße 88, 09126 Chemnitz, Germany

3) Konzernforschung - Werkstoff und Fertigungsverfahren, enrico.körner@volkswagen.de, Volkswagen AG, Brieffach 011/14990, 38436 Wolfsburg, Germany

4)ZZoltek Corporation, manuel.schlegel@zoltek.com, c/o Toray International Europe GmbH, Hugenottenallee 175, 63263 Neu-Isenburg, Germany

\section{Keywords}

Hybrid Textiles, Load-adapted Composite Design, Media-based Impregnation, Thermoplastic Composites

\begin{abstract}
The potential of a continuous non-crimp fabric (NCF) process with implemented offset technologies is demonstrated by a case study of a seat pass-through. Topology optimization with the relevant load cases and the construction of a load-adapted composite design with a weight saving of up to 18 percent is presented. Inverse draping identifies a two-dimensional development of the construction and prepares it for production based on the restrictions of textile technology. The downstream process capability of textiles produced in this way was investigated by impregnating heavy tows with polypropylene on laboratory scale and subsequent material characterization of the resulting laminates. The impregnation and consolidation of the seat pass-through is performed with load path adapted semi-finished products using novel variothermal, fluid-based pressing. This allows better control over the dynamic impregnation and unwanted fiber washing due to the large gradient of the areal weight. The final processing in injection molding tool of the reference component shows the applicability of the technology also in existing process chains and illustrates the potential of the consistent consideration of a load-adapted composite design in the development process.
\end{abstract}

\section{Introduction}

The transformation of mobility in the private and transport sector towards electromobility and autonomous driving requires lighter and function-integrated component approaches. However, special attention must be paid towards the economic attractiveness of new materials and technologies. The integration of cost-intensive battery technologies, sensors and controls must be compensated in terms of weight, cost and functionality. Thermoplastic polymers and their processing offer a high potential to solve this challenge. Fiber-reinforced thermoplastics can also outperform the mechanical properties of metallic materials when aligned along the component load paths. However, the economic application of carbon fibers is limited due to the design freedom of conventional fiber composite semi-finished products. 
Previous research and process development of tape and tow-laying technologies has primarily addressed unidirectional, near-net-shape applications and partial reinforcements for tailored blanks [1]. As an approach for to reduce costs by increasing the material efficiency of fiber-reinforced composites, a continuous NCF process with implemented warp and weft offset technologies was developed [2]. This allows for the production of cost-effective glass fabrics with carbon fibers applied with variable curvature on the top side and a parallel embedding of semi-finished polymer materials. Furthermore, the impregnation of fabrics produced in this way with a small gradient of areal weight was studied [2-4].

In the work presented here, the possibilities of large-scale production on a warp-knitting machine with offset technologies are demonstrated based on a component study of a load-adapted seat pass-through. For the practical implementation of a demonstrator, preparatory laboratory tests were carried out for the thermoplastic impregnation of heavy tow carbon fibers with a polypropylene matrix. The results of the design and preliminary tests were applied to the textile production, to the production of pre-impregnated laminates with a fluid-based pressing process and lastly to the final injection molding process.

\section{Load-adapted design approach for a seat pass-through}

\subsection{Reference analysis}

The reference structure of the study is a seat pass-through developed by the Department of Lightweight Structures and Polymer Technology (SLK) of Chemnitz University of Technology and partners, which was produced with an 8-layer unidirectional glass fiber layup and glass fiber-reinforced injection molding material (see Figure 1) [5].

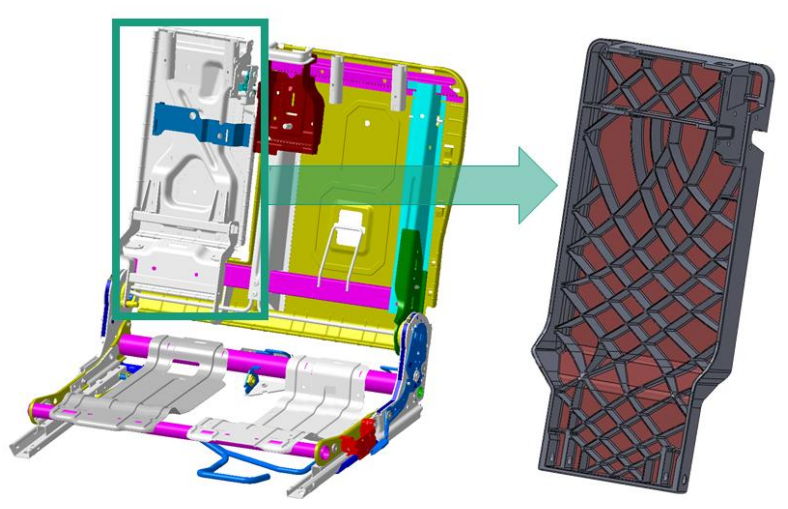

Figure 1: Steel seat pass-through in assembly (left) and the reference composite seat pass-through (right)

Three static load cases were considered for this component, shown in Figure 2. The two-stage crash load case (Figure 2, right) with a maximum displacement of $100 \mathrm{~mm}$ is the most critical of the three load cases for the component structure. Here, reinforcing carbon fibers can offer an advantage in component performance. 

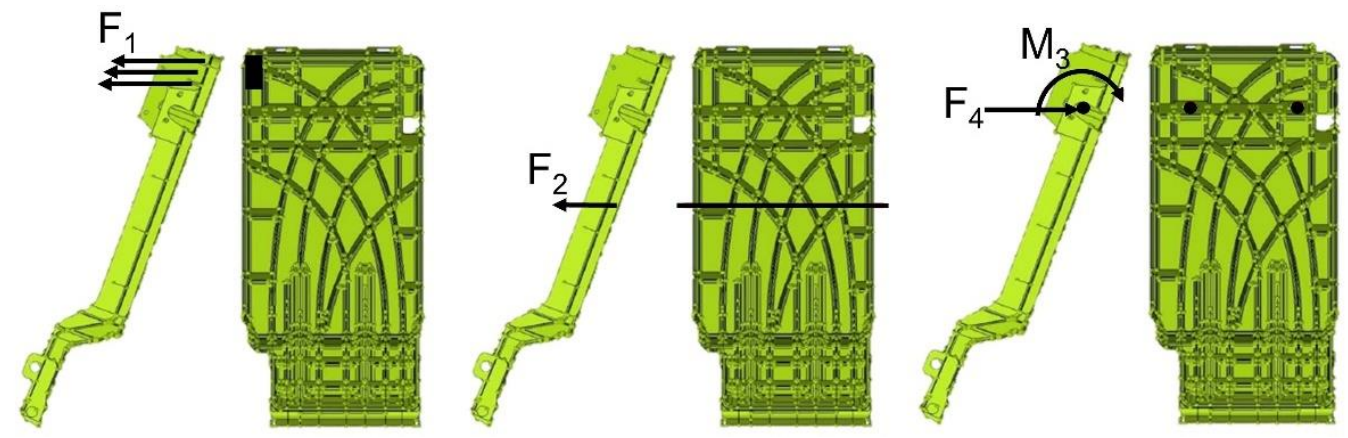

Figure 2: Static load cases for belt tension (left), trunk load (middle) and rear impact (right)

The reference component consists of a $\left[-45^{\circ}{ }_{3} /+45^{\circ}\right]$ s glass fiber organic sheet with a thickness of $2 \mathrm{~mm}$. The remaining part of the component consists of glass fiber-reinforced polypropylene. The reference structure was modeled on the Finite Element Method (FEM) based simulation package ANSYS Workbench with the relevant load cases in order to establish a benchmark for the later optimization. The boundary conditions correspond to the three load cases described above. For example, in case of a rear-end crash the passenger's head would be supported by the headrest while the back of the passenger would be pushed against the center of the component. This dynamic load case is translated into a two-step static load case in which the headrest forces are idealized by a remote force that is initialized at $0 \mathrm{~N}$ and increases to $2400 \mathrm{~N}$ in the second step. Meanwhile, another force in the middle of the part starts at $11,500 \mathrm{~N}$ and decreases to $4000 \mathrm{~N}$ in the second load step.

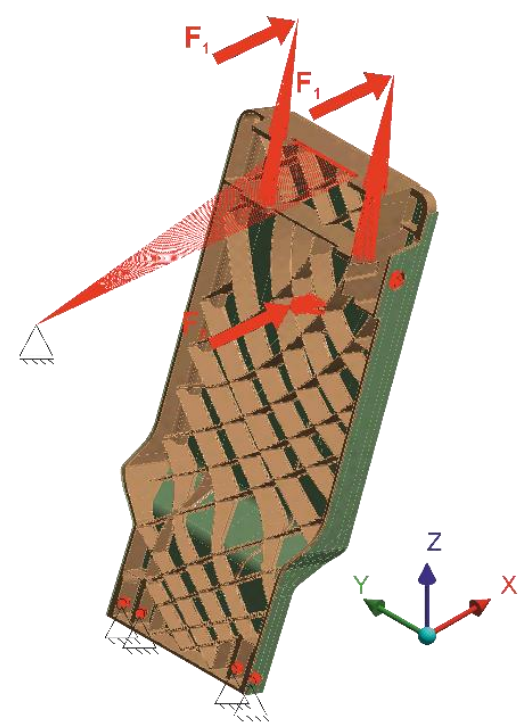

Figure 3: Definition of static boundary conditions in case of rear crash load case

\subsection{Conception and calculation of a load-compatible seat pass-through}

As a first step, the load paths through the geometry should be identified. For this purpose, the entire component is defined as an isotropic material and simulated with the three load cases. In ANSYS Workbench the topology optimization can be configured to retain a certain fraction of the total volume ( $25 \%$ in this case). Load case 2 (trunk load) is similar in its result to load case 3 (rear crash) which is more critical. Load-case 2 was therefore ignored for further design iterations. The raw result of the topology optimization is shown in Figure 4. This result was further analyzed in order to extract a textile composite relevant geometry. 


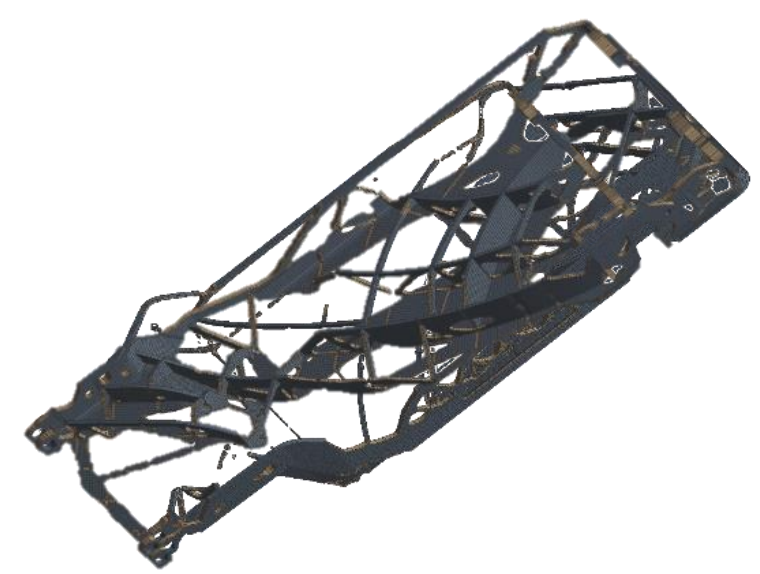

Figure 4: Result of the topology optimization

The boundary conditions for the complexity and design of hybrid textiles are as follows:

- The sample geometry can be produced under plant restrictions

- A maximum of two different patterns which are combined by film stacking in the production of organic sheets

- $\quad$ Each load path is defined by at least three parallel rovings with a laying width of $10 \mathrm{~mm}$ each

- $50 \mathrm{k}$ carbon fiber tow for the entire structure

- Extension of the original organic sheet volume around the outer ridge

- Top and bottom cover layer in the form of a $300 \mathrm{~g} / \mathrm{m}^{2}, \pm 45^{\circ}$ and $0.12 \mathrm{~mm}$ thick glass organic sheet

- Organic sheet thickness of max. $2 \mathrm{~mm}$

- Transfer of the load path analysis in the injection mold for component investigation

- Material data for glass and injection molding material according to the reference component

- The data for the carbon fiber UD tape material is based on a Celanese product available on the market

Based on the manufacturing constraints and the boundary conditions described above, a load-adapted design was proposed. The orientation and thickness of reinforcements were validated and optimized by further simulations. The final reinforcement pattern with an optimum thickness of $0.8 \mathrm{~mm}$ load paths per pattern is shown on the left in Figure 5. The layup in the crossover areas is shown on the right in Figure 5 . Note that each pattern consists of two layers of tapes, each $0.2 \mathrm{~mm}$ thick.
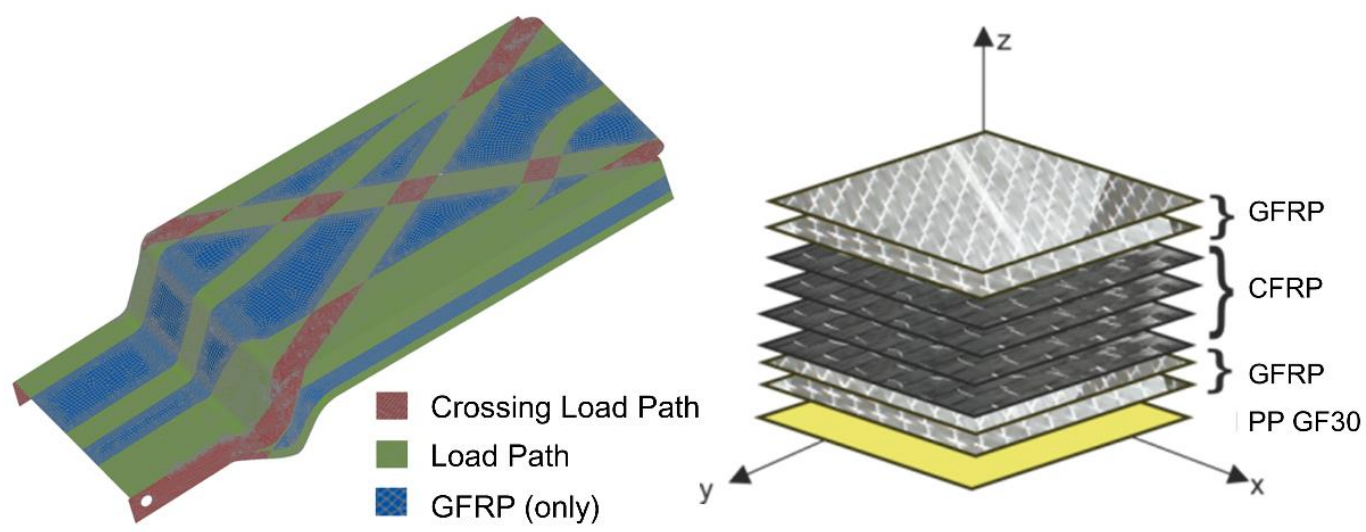

Figure 5: Model of a load-adapted seat pass-through (left) and layup of a load path cross section (right)

The calculation results of the reference structure and the load-adapted seat pass-through are shown in Table 1. Both the reference structure and the optimized variant have a sufficiently small displacement of less than $100 \mathrm{~mm}$ in load case three. However, this is due to the use of static equivalent load cases. 
Based on the results, it can be assumed that the load path adapted variant fulfills this criterion with a weight saving of up to $18 \%$. It should be noted that the high principal stress values in load case 3 appear to be due to mesh irregularities at certain geometric transition points. Apart from a few localized irregularities, the principal stress values throughout the part were well below $500 \mathrm{MPa}$ (see Figure 6).
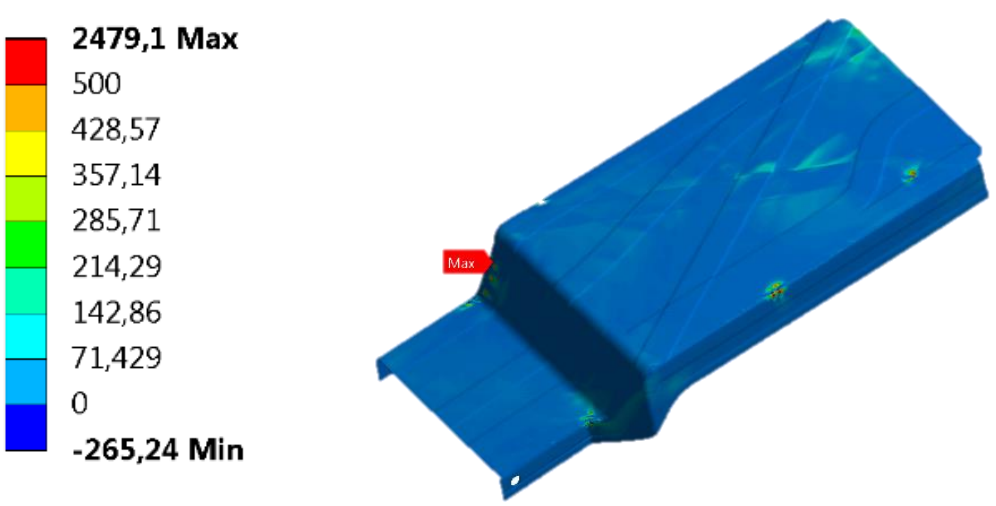

Figure 6: Maximum principal stresses in the optimized layup under load case 3

Table 1: Comparison between the stiffness and strength results of reference and load path adapted seat pass-through

\begin{tabular}{llll}
\hline Parameter & Unit & Reference & Load-adapted design \\
\hline Load Case 1 & & & \\
\hline$U_{\max }$ & $\mathrm{mm}$ & 2.58 & 7.19 \\
$\sigma_{1 \max }$ & $\mathrm{MPa}$ & 37.82 & 237.48 \\
\hline Load Case 3 & & & \\
\hline$U_{\max }$ & $\mathrm{mm}$ & 20.18 & 17.25 \\
$\sigma_{1 \max }$ & $\mathrm{MPa}$ & 167.08 & 2479.1 \\
$m_{\text {Tape }}$ & $\mathrm{Kg}$ & - & 0.18 \\
$m_{\text {Injection molding }}$ & $\mathrm{Kg}$ & 1.82 & 1.63 \\
$m_{\text {GFRP }}$ & $\mathrm{Kg}$ & 0.53 & 0.11 \\
$M_{\text {Total }}$ & $\mathrm{Kg}$ & 2.35 & 1.92 \\
$\Delta U_{\text {LF1 }}$ & $\%$ & - & 179.1 \\
$\Delta U_{\text {LF3;LS2 }}$ & $\%$ & - & -14.52 \\
$\Delta m_{\text {Total }}$ & $\%$ & - & -18.3 \\
\hline
\end{tabular}

\section{Thermoplastic process chain of a load-adapted demonstrator}

\subsection{Thermoplastic impregnation of heavy tow carbon fibers}

In preparation for the further processing of hybrid textiles with heavy tow carbon fibers and glass fibers in combination with a polypropylene matrix, the impregnation and the influence of different parameters were subject to a laboratory-scale investigation. The material for this investigation was a hybrid textile with a non-crimp fabric base layer of $\pm 45^{\circ}$ glass fibers and an additional $0^{\circ}$ UD carbon fiber layer, which was partially applied to the textile surface. The processed materials were Zoltek PX35 50k carbon fibers and EC14-300 glass fibers; the polypropylene is available as a film, which allows for an even distribution in the layup. As Figure 7 shows, the positioning of the carbon fibers leads to a carbon fiber covered 
surface with a gap in between where only the glass fiber base material is present. The focus of all microscopic and mechanical investigations is only on those areas of the laminate where carbon fibers are placed which can be described as $\left[0^{\circ} \mathrm{CF} / \pm 45^{\circ}{ }_{2} \mathrm{GF}\right] \mathrm{s}$.

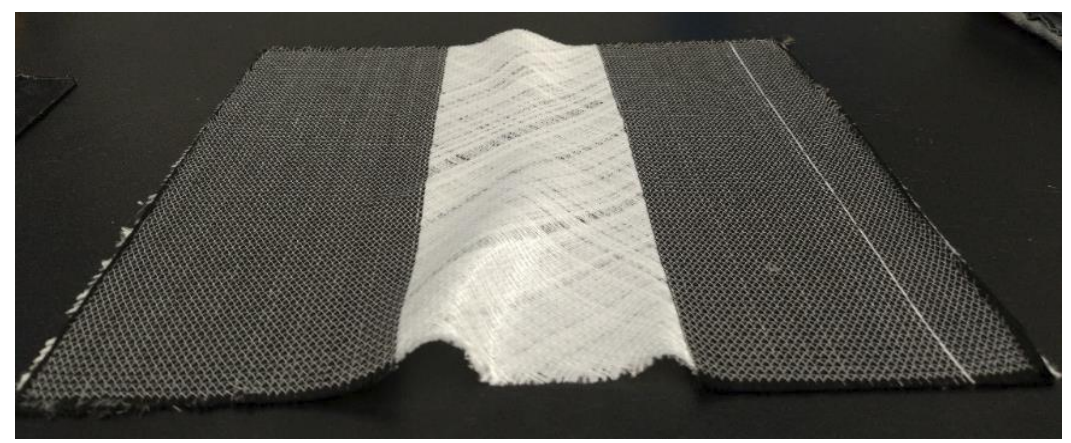

Figure 7: Hybrid fabric with glass fiber base layer and locally placed carbon fibers

The temperature profile for the pressing process includes heating to $240{ }^{\circ} \mathrm{C}$, maintaining this temperature at an applied surface pressure of 12 bar for 2 minutes and then cooling the laminate to 80 ${ }^{\circ} \mathrm{C}$. Using two different presses with the same pressing parameters, the significance of the duration of the high-temperature phase is shown. Whilst press $A$ reaches the maximum temperature after 9 minutes, press $B$ needs more than 50 minutes. The cross-section of the laminates show significant differences. In the composite produced with press A only $\sim 60 \%$ of the carbon fibers are impregnated, whereas laminate $B$ reaches a wet content of more than $85 \%$ of the carbon fibers. The carbon fiber layers covering the glass layers can be seen in Figure 8. Here, the dark areas in the carbon fiber roving are dry, while the bright areas are well impregnated. Samples for tensile testing are produced to gain information about the mechanical values. The tensile modulus shows no difference between the different laminates, both reach the mark of $46 \mathrm{GPa}$. However, differences could be seen between the tensile strengths of laminate A and B with values of $405 \mathrm{MPa}$ and $504 \mathrm{MPa}(20 \%$ higher than A) respectively. This shows that the slower the heating and thus the longer the high temperature phase, the better the material performance.

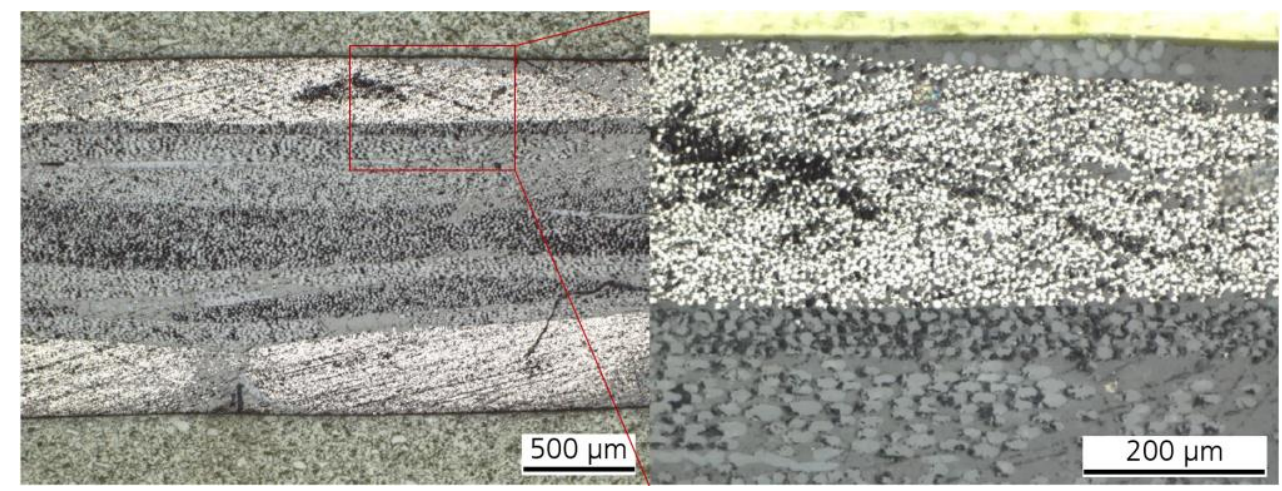

Figure 8: Microscopic cross-section of a $\left[0^{\circ} \mathrm{CF} / \pm 45^{\circ}{ }_{2} \mathrm{GF}\right]$ s laminate

Due to the locally placed carbon fiber reinforcements, the textile does not have a consistent thickness. To investigate the influence of the jumps in thickness, a layup is created in which a thickness compensation with a PTFE film is realized. The problem without any compensation is that the pressure during the pressing process is not distributed evenly over the surface of the plaque - the thicker areas are exposed to a higher pressure. These circumstances cause the material flow, which means that the carbon fibers cannot hold their intended position and tend to move towards the thinner areas. By using additional material to balance the thickness, the pressure distribution becomes uniform and more controllable, so that the reinforcements keep their actual positions. 


\subsection{Production of hybrid textiles}

In order to carry out the component study, the part should be constructed in accordance with the production requirements. This includes not only the manufacturing restrictions of textile technology, but also the subsequent steps to ensure the impregnation of the semi-finished products and further processing.

In the first step, the three-dimensional load path geometry was processed by an inverse draping algorithm to the two-dimensional plane and then separated into the two resulting patterns (see Figure 9). This two patterns were further resolved for warp displacement technology and resulted in a main pattern $\mathrm{P}^{\mathrm{M}}$ of six three-roving reinforcements and a cross pattern $\mathrm{P}^{\mathrm{C}}$ of two three-roving reinforcements.

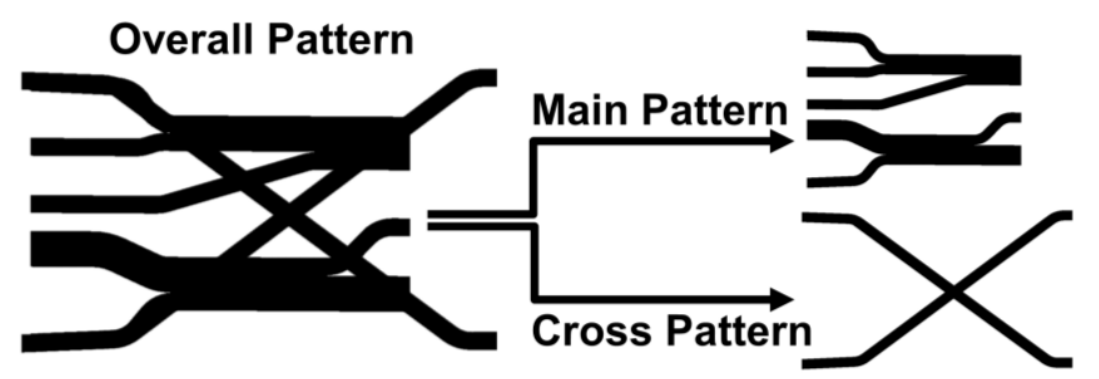

Figure 9: Overall pattern and derived sub-patterns

The fabrics were produced in a large-scale continuous process with a speed of up to $3.5 \mathrm{~m} / \mathrm{min}$ using Zoltek PX35 carbon fibers and EC14-300 glass fibers. The pattern of the rovings was iteratively adjusted to match the suggested designed by visual inspection. The $\mathrm{P}^{\mathrm{M}}$ was applied once to a pure polypropylene matrix film and again to a matrix film together with a glass NCF \pm 45 GF (see Figure 10). This GFRP sheet at the bottom acts as interface to the injection molding material (see Figure 5, right). The $\mathrm{P}^{\mathrm{C}}$ was produced on the matrix film only. A separate glass NCF \pm 45 GF for the top of the layup was produced.

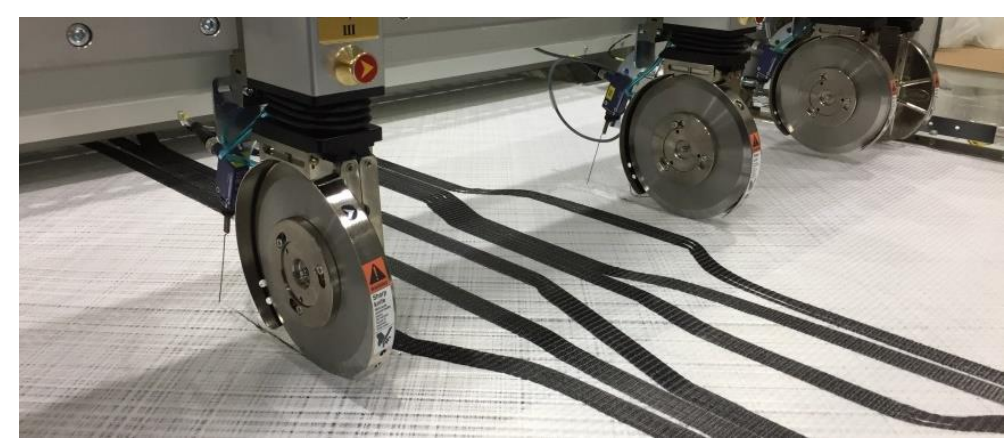

Figure 10: Textile production following the main pattern

During subsequent cutting, the load path patterns were separated from the excess plastic film and reduced to the length necessary for impregnation. The fabric with glass NCF was trimmed to the required size.

\subsection{Impregnation of hybrid textiles on thermoplastic prepregs}

Based on the findings of the laboratory tests, textiles and films were pressed into a laminate in a variothermal and static pressing process. Impregnation in the flat plate tool was not as ineffective as shown in the laboratory tests. Therefore, sheet metal stencils with a thickness of $0.65 \mathrm{~mm}$ were produced for both types of patterns to complement the layer structure at both the top and bottom and compensate for the jumps thickness. The planned width of the carbon fiber reinforcement was increased from $30 \mathrm{~mm}$ to $40 \mathrm{~mm}$ in the patterns because the width of the applied reinforcements varied between $30-35 \mathrm{~mm}$ and in the position absolute $2.5 \mathrm{~mm}$. A laminate layer thickness of $0.305 \mathrm{~mm}$ results when 
using three layers of matrix film per reinforcment pattern with fully spread rovings. The reinforcements therefore ideally have a thickness of $0.61 \mathrm{~mm}$, but vary to $0.65 \mathrm{~mm}$ due to local differences in width. The reinforcement patterns as well as additional layers of film were pre-fixed on the glass NCF substrate. Both layups, one for construction $\left[ \pm 45 \mathrm{GF} / \mathrm{PM}_{2} / \mathrm{PC}_{2} / \pm 45 \mathrm{GF}\right.$ ] and the other for demonstration with external load paths $\left[ \pm 45 \mathrm{GF} / \mathrm{PM}_{2} / \mathrm{PC}_{2}\right]$ were manufactured.

The pressure, temperature and time parameters from Figure 11 were used for the pressing process. The duration of the pressing process varied by \pm 5 minutes due to production reasons. On average, the production time was $73 \mathrm{~min}$. The tempering pressure $p_{\uparrow}$ was set to 5 bar surface pressure. After reaching the target temperature $\vartheta_{H}=230^{\circ} \mathrm{C}$, the pressure was increased to $p_{\rightarrow}=10$ bar and maintained for the time $t_{H}=5 \mathrm{~min}$. Finally, the part was cooled down to the demolding temperature of $\vartheta_{E}=120^{\circ} \mathrm{C}$.

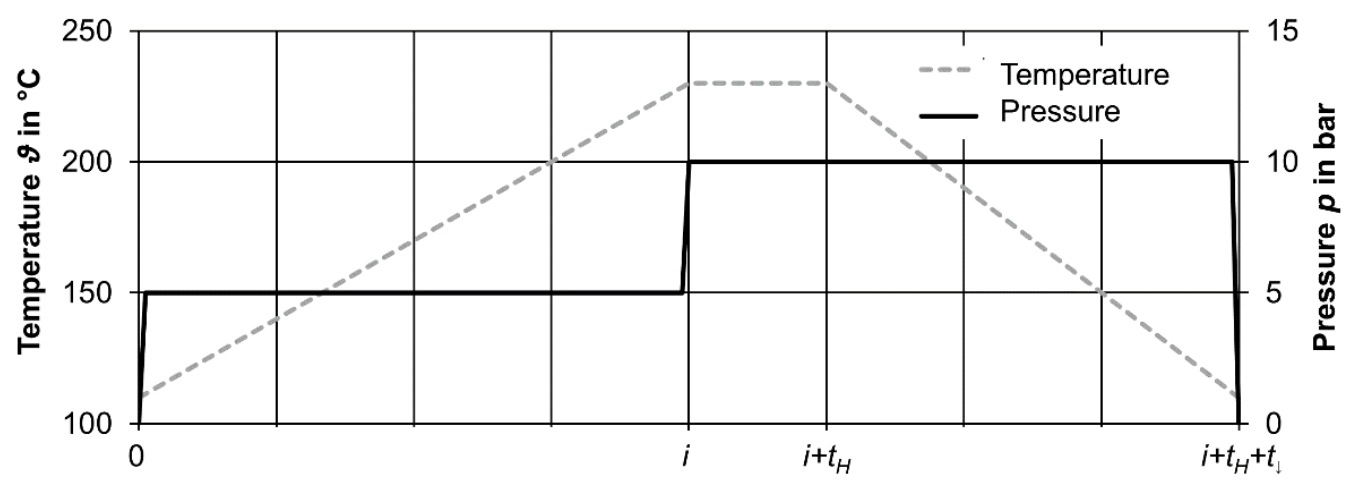

Figure 11: Idealized pressure-temperature-time parameters of the impregnation process

The laminates could not be successfully impregnated and consolidated, neither by providing the load path structure in the tool with a stencil nor by utilizing a specific mold. The main challenge here is the dynamic process of impregnation. While the thickness of the laminate is correctly maintained by the construction of the stencil, the thickness of the un-impregnated structure is not maintained. During this dynamic process, the stencil in the layup is subjected to relatively little stress. When tempered to $230^{\circ} \mathrm{C}$, the polypropylene melts and flows in the direction of the pressure gradient, i.e. away from the load paths. Fibers are pulled along in this flow process and cause so-called fiber washing. A silicone tool leads to an improvement here, but also causes local differences in the pressure conditions.

The solution here is a variothermal fluid-based upper mold (see [6-7]), which distributes the pressure evenly over the laminate. The stencils delimit the edge area of the load paths and the fluid pressure acts uniformly via a release film on the load paths themselves. Experimentally, this was realized by means of a Teflon cushion filled with a low-melting material. This principle can be integrated directly into an upper mold and thus the filling material can also be used as a tempering medium to significantly reduce cycle times. Figure 12 (left) shows a semi-finished product after waterjet cutting with external reinforcements. Undulations can be seen here within the stencil border at the edges (see Figure 12, right). This is due to fraying caused by pre-fixing and slight misalignment during stacking of the sheets. The width of the laid reinforcements was maintained due to the hydrostatic pressure. After microscopic examination of the cross-section, no delamination or dry filaments could be observed. 

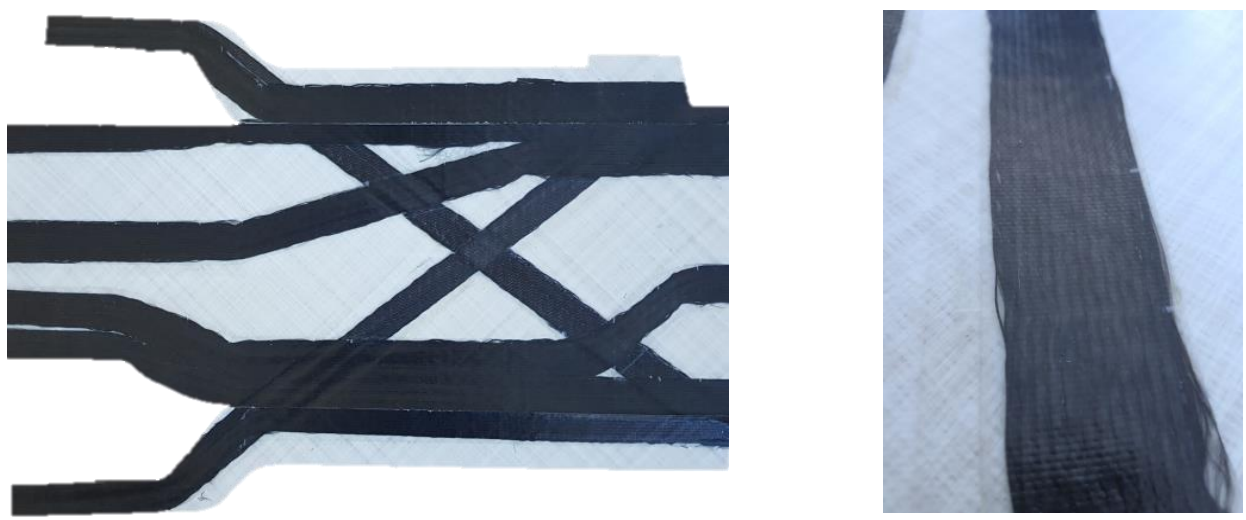

Figure 12: Semi-finished product with upper load paths (left) and load path (right)

\subsection{Demonstrator production in injection molding}

For the production of the component, the original injection molding tool of the reference structure was used on an Engel Insert 1800H / 400 with auxiliary unit IU500L. As injection molding material Scolefin $52 \mathrm{G} 13$ - 0 was used. The screw temperature was a maximum of $240{ }^{\circ} \mathrm{C}$, the mold was heated to $70{ }^{\circ} \mathrm{C}$. Due to a groove along the circumference of the tool, the additional side parts were separated from the organic sheet and formed before injection molding. The laminate for the original sheet area was formed directly when the tool was closed. The tempering of this semi-finished product was carried out in a convection oven at $175^{\circ} \mathrm{C}$. The edge areas were flooded with sufficiently hot injection molding compound to achieve adhesion.

The comparatively thin glass fiber sheets as well as the highly thermally conductive carbon fiber areas placed increased demands on the necessary process speed from handling to the injection process. The process employs a turnover board and a tool design with sprue in the upper mold, which must close before the injection unit can be docked. This results in a significant dwell time of the organic sheet in the mold. The temperature losses in the middle of the organic sheet could not be compensated, which in turn causes a reduced adhesion of the rib structure. By optimizing the process with variothermal tool surfaces, a substantial improvement in adhesion could be achieved.

Nevertheless, the processability of hybrid laminates with load-adapted fiber architecture could be demonstrated. Figure 13 shows a pass-through demonstrator produced with external load paths.

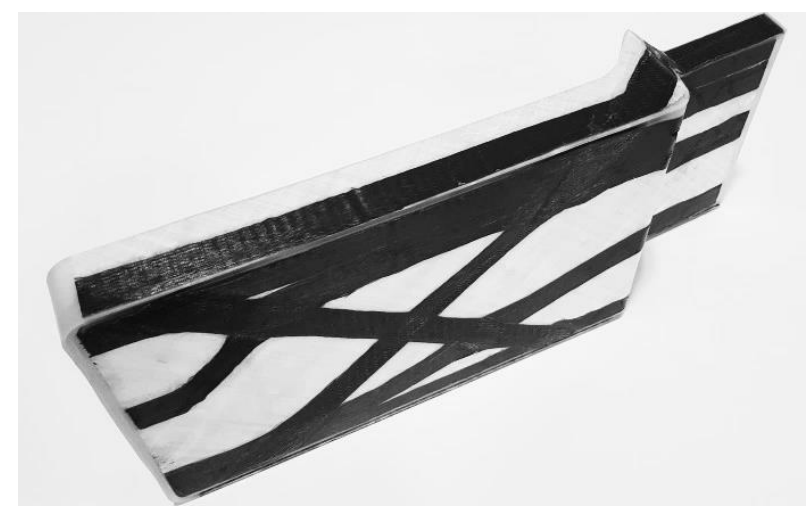

Figure 13: Load-adapted seat pass-through with external load paths 


\section{Discussion and conclusion}

\subsection{Summary}

From an economic point of view, carbon fiber reinforced plastics are currently less competitive compared to other materials, especially in the automotive sector. High costs for base materials as well as limitations in the ability to process them with maximum resource efficiency in processing lead to a negative image of this material.

In the present study it could be shown that inexpensive carbon fiber heavy tows in combination with polypropylene as matrix material can be further processed. With the help of a load-adapted textile technology, the degrees of freedom in the design of fiber composite semi-finished products were extended and the savings potential of a seat pass-through, which has already been optimized with a glass fiber organic sheet, is shown. The large-scale production on the textile level could be demonstrated. For a successful impregnation of such textiles a fluid-based variothermal press was tested. The final production of the components in injection molding could be carried out, indicating the need for customized injection molding tools and thermally efficient processes for such applications.

\subsection{Outlook}

Further research in textile technology should be based on accuracy and reproducibility as well as on a further increase in production speed. The concept for impregnation could be further developed as an independent upper form to an accelerated variothermal pressing process or transferred to the upper punch of an interval heating press. For further processing in injection molding, the future use of nearsurface temperature control of the injection molds can be considered, for example by an external induction coil. Further optimization of the component construction is possible, for example, by designing tapes with variable widths or thicker tapes or even by using different types of carbon fibers within the component. Taking the above suggestions for improvement into account, future component tests and behavior during the use phase are conceivable.

\section{References}

[1] Yassin, K.; Hojjati, M.: Processing of thermoplastic composites through automated fiber placement and tape laying methods: A review. Journal of Thermoplastic Composite Materials 12 (2017), pp. 1676-1725.

[2] Mittmann, A.; Naumann, M.; Körner, E.: Kraftflussgerechte Faserverbunde mit Thermoplastmatrix. Kunststoffe, 9(2018), pp. 150-154.

[3] Naumann, M.; Körner, E.; Mittmann, A.: Imprägnierstrategie für kraftflussgerecht gestaltete endlosfaserverstärkte Thermoplaste. TextilPlus, 11/12(2016), pp. 32-35, 2016.

[4] Heinecke, T.: Entwicklung einer Technologie für einen hybriden Faserverbund aus Gelegestrukturen mit lastpfad- und kraftflussgerechten Strukturen. 16. Chemnitzer Textiltechnik Tagung 2018.

[5] Bauer, M.; Wallasch, R.; Tirschmann, R.; Spieler, M.; Nendel; W.; Kroll, L.: Automatisiertes Herstellungsverfahren für gewichtsreduzierte und belastungsoptimierte Hybridstrukturen, hergestellt im großserientauglichen Spritzgießprozess (HySpri). Poster zum PaFa Therm II Mehrkomponenten-Spritzgießprozesse für strukturvariable textilverstärkte Verbundbauteile, Chemnitz, 2014.

[6] Chang, J.-H.; Yang, S.-Y.: Development of fluid-based heating and pressing systems for micro hot embossing. Microsystem Technologies, 11(2005), pp. 396-403.

[7] Chang, J.-H.; Yang, S.-Y.: Development of rapid heating and uniformly pressing system for micro hot embossing. ANTEC 2004, pp. 942-945. 